\title{
Psychometric Properties of the Form Development of Self-Care Competence of the Person with a Bowel Elimination Ostomy
}

\author{
Propriedades Psicométricas do Formulário Desenvolvimento da Competência de Autocui- \\ dado da Pessoa com Ostomia de Eliminação Intestinal \\ Propiedades Psicométricas del Formulario Desarrollo de la Competencia del Autocuidado \\ de la Persona con Ostomía de Eliminación Intestinal \\ Igor Emanuel Soares Pinto*; Célia Samarina Vilaça de Brito Santos**; \\ Maria Alice Correia de Brito***; Ś́lvia Maria Moreira Queirós****
}

\begin{abstract}
Background: The use of an instrument to assess the self-care competence in patients with bowel elimination ostomy allows for the systematic identification of their specific needs, ensuring the continuity of nursing care. Although an instrument that assesses the domains that integrate this competence has been developed in Portugal, it has not yet been validated.

Objectives: To assess the psychometric properties of the form Development of Self-Care Competence of the Person with a Bowel Elimination Ostomy.

Methodology: Methodological study aimed at analyzing the psychometric properties of a measurement instrument, written in Portuguese.

Results: The Cronbach's alpha was 0.95 and the inter-rater reliability showed a correlation greater than or equal to 0.98. A statistically significant correlation was found in the split-half test, as well as in the clinical sensitivity analysis.

Conclusion: The form presented good psychometric indicators, which suggests that it is a useful tool to be used in the nursing diagnosis process, thus contributing to the optimization of nursing care.
\end{abstract}

Keywords: self-care; ostomy; validation studies; nursing care

\section{Resumo}

Enquadramento: A utilização de um instrumento de avaliação da competência de autocuidado na pessoa com ostomia de eliminação intestinal permite a identificação das suas necessidades específicas de forma sistematizada, assegurando a continuidade dos cuidados de enfermagem. Foi desenvolvido em Portugal um instrumento que avalia os domínios que integram essa competência, contudo, não se encontra validado.

Objetivos: Avaliar as propriedades psicométricas do formulário Desenvolvimento da Competência de Autocuidado da Pessoa com Ostomia de Eliminação Intestinal.

Metodologia: Estudo metodológico para análise das propriedades psicométricas de um instrumento de medida, escrito em português. Resultados: $\mathrm{O}$ alfa de Cronbach foi de 0,95 e a fidelidade interjuízes demonstrou uma correlação igual ou superior a 0,98 . No teste de split-half verificou-se uma correlação estatisticamente significativa, assim como no estudo da sensibilidade clínica.

Conclusão: $\mathrm{O}$ formulário apresentou bons indicadores psicométricos, sugerindo a viabilidade da sua utilização enquanto ferramenta proficiente para o processo de diagnóstico de enfermagem, contribuindo para a otimização dos cuidados de enfermagem.

Palavras-chave: autocuidado; ostomia; estudos de validação; cuidados de enfermagem

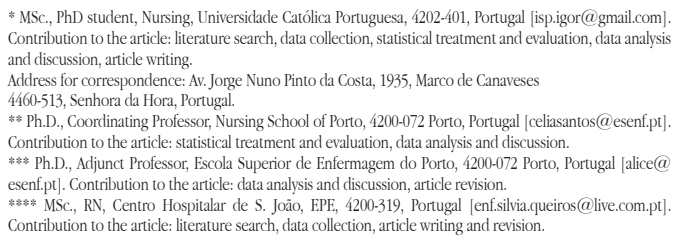

* MSc., PhD student, Nursing, Universidade Católica Portuguesa, 4202-401, Portugal [isp.igor@gmail.com]. Contribution to the article: literature search, data collection, statistical treatment and evaluation, data analysis and discussion, article writing.

Address for correspondence: Av. Jorge Nuno Pinto da Costa, 1935, Marco de Canaveses 4460-513, Senhora da Hora, Portugal.

**. Ph.D., Coordinating Professor, Nursing School of Porto, 4200-072 Porto, Portugal [celiasantos@esenf.pt]. Contribution to the article: statistical treatment and evaluation, data analysis and discussion. *** Ph.D., Adjunct Professor, Escola Superior de Enfermagem do Porto, 4200-072 Porto, Portugal [alice@ esenf.pt]. Contribution to the article: data analysis and discussion, article revision.

***** MSc., RN, Centro Hospitalar de S. Joăo, EPE, 4200-319, Portugal [enf.silvia.queiros@live.com.pt]. Contribution to the article: literature search, data collection, article writing and revision

\section{Resumen}

Marco contextual: El uso de un instrumento de evaluación de la competencia del autocuidado en la persona con ostomía de eliminación intestinal permite identificar sus necesidades específicas de forma sistematizada, lo que asegura la continuidad de los cuidados de enfermería. Se desarrolló en Portugal un instrumento que evalúa los dominios que forman dicha competencia, aunque no está validado.

Objetivos: Evaluar las propiedades psicométricas del formulario «Desarrollo de la competencia del autocuidado de la persona con ostomía de eliminación intestinal».

Metodología: Se trata de un estudio metodológico de las propiedades psicométricas de un instrumento de medición escrito en portugués.

Resultados: El alfa de Cronbach fue de 0,95 y la fidelidad interjueces demostró una correlación igual o superior a 0,98. En la prueba de división por mitades se verificó una correlación estadísticamente significativa, así como en el estudio de la sensibilidad clínica.

Conclusión: El formulario presentó buenos indicadores psicométricos y sugiere la viabilidad de su uso como una herramienta apta para el proceso del diagnóstico de enfermería, lo que contribuye a la optimización de los cuidados de enfermería.

Palabras clave: autocuidado; ostomía, estudios de validación, atención de enfermería

Received for publication: 30.07 .15

Accepted for publication: 29.01.16 


\section{Introduction}

Approximately one million patients undergo stoma-forming surgery every year worldwide (Simmons, Smith, Bobb, \& Liles, 2007). In Portugal, it is estimated that around 20.000 patients have one or more elimination ostomies (Cabral, 2009).

Stoma-forming ostomy is a transforming event in the patient's life, both physically and psychologically (Gesaro, 2012), since it affects the patient's body, self-image, self-esteem, confidence and independence, leading to changes in social relationships, modes of dressing, diet, sexuality and/or at work (O'Connor, 2005).

The experience of this event is conditioned by several factors, particularly the stoma care competence, as a contributing factor to the process of stoma adjustment (Simmons et al., 2007).

Therefore, the nurse plays a central role in the training process of the ostomy patient. It is essential for therapeutic success that the nurse has acquired the necessary tools to aid the decision making process within this field of intervention. With this study, we aimed to analyze the psychometric properties of the form "Development of Self-Care Competence of the Person with a Bowel Elimination Ostomy", providing nurses with an instrument that may facilitate the process of identifying the specific needs of the ostomy patient.

\section{Background}

Patients living with a stoma have to develop competence to cope with their new condition, namely self-management skills and skills to manage every aspect of their lives (Gesaro, 2012).

In recent years, the concept of competence has been increasingly addressed from different perspectives and in different contexts, namely at the academic and organizational level. The concept of competence is associated with: knowing how to act, mobilizing resources, integrating multiple and complex knowledge, knowing how to learn, knowing how to adjust, taking responsibility, and having a strategic vision (Fleury \& Fleury, 2001).

Thus, competence is understood as "knowing how to act in a responsible and recognized way that implies mobilizing, integrating, transferring knowledge, resources and skills..." (Fleury \& Fleury, 2001, p. 188).

As regards the concept of self-care in ostomy patients, it can be understood as the patients' ability to apply their stoma management skills (O'Connor, 2005).

The use of standardized, simple and easy-to-use tools can improve the clinical description and minimize the discrepancies in the assessment performed by health professionals. Therefore, an instrument to measure the patients' competence in stoma self-care is a useful tool for the identification of their specific needs, thus allowing for a more targeted and personalized intervention and, consequently, an improvement of the transition process and of the quality and continuity of care. Among the available instruments concerning the patient with bowel elimination ostomy, no instrument on self-care had yet been validated for the Portuguese population. The instrument developed by Cardoso (2011), Silva (2012) and Gomes (2012), entitled Development of Self-Care Competence of the Person with a Bowel Elimination Ostomy, covers all of the domains of the self-care competence; however, it was not validated, having only been tested in community, preoperative and hospitalization settings, in independent research studies. In view of the above, we established the goal of assessing the psychometric properties of this measurement instrument, with the purpose of contributing to the optimization the process of data collection by the nurse, in particular regarding the identification of the care needs of the patient with a bowel elimination ostomy.

\section{Research Question}

The following research question was formulated: Does the form "Development of Self-Care Competence of the Person with a Bowel Elimination Ostomy" have valid psychometric properties?

\section{Methodology}

The study sample was composed of patients waiting for surgery with possible stoma formation and patients with a bowel elimination ostomy, being followed-up in four hospitals of the Greater Porto region and in three clusters of health care centers of the north region of Portugal. 
We used the nonprobability convenience sampling technique to select the participants, and calculated the sample size as proposed by Bryman and Cramer (1992), according to whom, for purposes of validity of a measurement instrument, the number of participants in the sample must be at least five times the number of items of the scale being used. Thus, given that the instrument under study is composed of 45 items, the sample was composed of 225 participants.

The following inclusion criteria were used: patients waiting for surgery with possible stoma formation or patients with a bowel elimination ostomy; being 18 years of age or older; having accepted to participate in the study; having no cognitive impairments, identified, when necessary, through the Mini-Mental State Examination (Guerreiro et al., 1994); and being independent in bowel elimination ostomy self-care.

The sampled participants were mostly male (63.1\%), with a mean age of 62 years ( $S D=12.78$ years), married $(76.9 \%)$, retired $(58.7 \%)$ and who had attended school (89.8\%). As regards the level of education, the mode was 4 years of basic education.

The most common pathologies leading to an ostomy were rectal neoplasia (55.1\%) and colon neoplasia (25.3\%), with temporary (47.6\%) colostomy $(77.8 \%)$ being the most prevalent type of ostomy.

Most participants included in the study had no contact with other ostomy patients (72.9\%), more than half of the participants attended preoperative nursing consultations (52.9\%), and $49.8 \%$ of the participants had their stoma site marked.

As regards the time elapsed since stoma formation, $5.8 \%$ of the participants were in the preoperative period, without ever having a stoma, 40.9\% were in the first month of the postoperative period (with an average of 13 days), and $53.3 \%$ were in the postoperative period for more than 1 month, with the average period being 3 years.

Most participants (70\%) had an informal care provider, usually the spouse or child.

Data were collected using the form "Development of Self-Care Competence of the Person with a Bowel Elimination Ostomy", which was previously designed by Cardoso (2011), Silva (2012), and Gomes (2012).

The process of building the instrument started with the definition of the concept of competence in elimination ostomy self-care. Subsequently, the indicators that allow for the assessment of the construct under analysis were identified, based on the
Nursing Outcomes Classification (NOC), the literature review, and the authors' professional experience.

Cardoso (2011), Silva (2012) and Gomes (2012) organized the information of the form based on the instrument developed by Schumacher, Stewart, Archbold, Dodd, and Dibble (2000) to assess the informal caregiver's ability to care, considering the multidimensional nature of the competence of stoma self-care. Based on this information, the authors identified six domains and their corresponding key indicators to assess stoma self-care competence: Knowledge (Kno) with nineindicators; Self-monitoring (SMo), with seven indicators; Interpretation (Int), with four indicators; Decision-making (DMa), with four indicators; Execution (Exe), with 17 indicators; and Negotiation and use of health resources (NRes), with four indicators.

The instrument is a 45 -item form that should be used by the interviewer (researcher/nurse) to evaluate (by asking questions and/or observing) the ostomy patient, using the indicators relating to each domain of the self-care competence in bowel elimination ostomy.

Structurally, the instrument is divided into two parts: the first part is composed of questions aimed to collect sociodemographic, clinical and treatment-related information; the second part is used to assess the stoma self-care competence.

The evaluation grid is a 5-point Likert-type scale, ranging from 1 to 5 , where: 1 corresponds to does not show, revealing that the ostomy patient has no self-care competence by meeting none of the outcome criteria defined for each indicator of the competence domain, and 5 corresponds to fully shows, considering that the ostomy patient has self-care competence by meeting all the outcome criteria defined for the indicators established for each competence domain.

The intermediate values relate to partially shows, where the ostomy patient shows a partial self-care competence by meeting at least one criterion, but not all, defined for each indicator of the competence domain. The scores between 2 and 4 vary according to the nurse's evaluation and relate to the number of outcome criteria shown for each indicator in the competence domains established in the guide for form completion which was specifically created for this purpose.

During the application of the form to patients waiting for stoma-forming surgery, only the Knowledge 
domain was assessed, with the option does not apply being marked for the remaining domains.

In the process of data collection, we requested the collaboration of nurses from different contexts to select the sample subjects, according to the criteria already defined, as well as to apply the form. To do so, the nurses received formal training on the instrument and how to use it.

Thus, data were collected by collaborating nurses from the clinical contexts and/or by the principal investigator, between April 2013 and May 2014.

After being collected, the data were analyzed using the SPSS software, version 20. The normality of variable distribution was analyzed using the Kolmogorov-Smirnov (KS) test, leading to the conclusion that age $(\mathrm{KS}=0.06 ; p=0.03)$ and education $(\mathrm{KS}=0.33 ; p=$ 0.000 ) had no normal distribution.

The analysis of the normality of item distribution showed that the items also had no normal distribution $(p<0.05$ in all items). On the other hand, the form domains had a normal distribution (Kno: $\mathrm{KS}=0.14$; $p=0.20$; SMo: $\mathrm{KS}=0.30 ; p=0.06$; Int: $\mathrm{KS}=0.22$; $p=0.20$; DMa: $\mathrm{KS}=0.19 ; p=0.20$; Per: $\mathrm{KS}=0.23$; $p=0.20$; NRes: $\mathrm{KS}=0.30 ; p=0.05$ ).

A measurement instrument must possess rigorous psychometric properties, such as validity and reliability, as well as clinimetric properties, which allow identifying the clinical relevance of the results, emphasizing reliable and significant clinical changes (Ribeiro, 2010).

Reliability was analyzed through the Cronbach's alpha, the split-half test and the interrater reliability test. Validity was analyzed through factor analysis and interdomain correlation.

During the planning stage of the research study, authorization to use and edit the instrument was requested to the authors. The study was also authorized by the Ethics Committees of the institutions involved. All participants were informed about the reasons to conduct the research, as well as its purpose and objectives. A document was provided so that the participants could formally express their free and informed consent to participate in the study. The participants were ensured of the confidentiality, as well as of the voluntary nature of the participation in the study, from which could withdraw at any moment

\section{Results}

Through the study of reliability, by analyzing the internal consistency of the form (Table 1), we found a Cronbach's alpha value of 0.95 , which indicates a good internal consistency (Ribeiro, 2010).

We analyzed the item-total correlation, observing that only the first and second items had correlations of -0.36 and 0.02 , respectively. The remaining items had a correlation greater than 0.30 . Given the theoretical relevance of the items, their exclusion is not recommended.

Considering the Cronbach's alpha values for each separate domain, we found that all items, with the exception of the Knowledge domain, had an alpha value greater than or equal to 0.80 . When considering the possibility of eliminating items in this domain, we found that, despite slightly increasing the Cronbach's alpha of the domain, there was no significant change. Additionally, the theoretical relevance of the items did not support their elimination. However, the values for all domains ranged from acceptable to good (Ribeiro, 2010).

In the process of data collection, we found a low response rate to item 41 (Performs the bowel irrigation technique) included in the Execution domain. Thus, seeking to understand the impact of items without a valid answer on determining the alpha value for this domain, this question was removed and the alpha value increased from 0.86 to 0.94 . However, considering the theoretical and practical relevance of the item, we have chosen to consider the Cronbach's alpha without its exclusion. 
Table 1

Cronbach's alpha of the domains and the form

\begin{tabular}{lcc}
\hline Domains & Number of items & $\begin{array}{c}\text { Cronbach's alpha } \\
(N=225)\end{array}$ \\
\hline Knowledge & 9 & 0.75 \\
Self-monitoring & 7 & 0.82 \\
Interpretation & 4 & 0.80 \\
Decision-making & 4 & 0.86 \\
Execution & 17 & 0.86 \\
Negotiation and use of health resources & 4 & 0.88 \\
Form & 45 & 0.95 \\
\hline
\end{tabular}

To further study the instrument's reliability, we also performed the split-half test, choosing to divide the form into two subgroups: a first subgroup with the even-numbered items $(\alpha=0.92)$ and another subgroup with the odd-numbered items $(\alpha=0.91)$. We could have considered other divisions, but the only way to eliminate the error associated with the various possibilities would be to consider all possible halves and establish the different relations between these halves. However, we used this division to assess the homogeneity and consistency of the construct to be assessed by the form, i.e. self-care competence. Through Pearson's correlation test, we found a positive, strong and statistically significant correlation $(r[7]=0.88 ; p=0.009)$ between both groups, indicating that the form has a good internal consistency between the two subgroups of items, which confirms that the instrument under is able to assess the major concept to which it was created.

In order to further assess the instrument reliability, we also analyzed the interrater reliability. To do so, using a sub-sample of 25 patients, the form was simultaneously completed by two observers/raters, and we subsequently analyzed the correlations between both observations (Fortin, 2003).

A high correlation was found between both raters' observations, particularly in the Knowledge, Interpretation and Decision-making domains (greater than or equal to 0.98 ). It was not possible to assess the level of agreement for the Self-monitoring and Negotiation and use of health resources domains because at least one of the raters selected the same response option in all items. This is considered a constant variable, which is why we were not able to calculate the correlation using the SPSS software.

Continuing with the assessment of interrater agreement, namely in the Execution domain, item 41 was deleted because all the participants $(n=25)$ selected the response option not applicable. After its deletion, we observed that the correlation was perfect, i.e. there was a total agreement between the answers from rater A and rater B. Table 2 presents these results. 
Table 2

Interrater correlation using Pearson's correlation test

\begin{tabular}{|c|c|c|c|c|c|c|}
\hline & $\begin{array}{c}\text { Knowledge } \\
\text { rater B }\end{array}$ & $\begin{array}{l}\text { Self-monitoring } \\
\text { rater B }\end{array}$ & $\begin{array}{c}\text { Interpretation } \\
\text { rater B }\end{array}$ & $\begin{array}{l}\text { Decision-making } \\
\text { rater B }\end{array}$ & $\begin{array}{l}\text { Execution }^{1} \\
\text { rater B }\end{array}$ & $\begin{array}{l}\text { Negotiation and } \\
\text { use of health } \\
\text { resources } \\
\text { rater B }\end{array}$ \\
\hline $\begin{array}{l}\text { Knowledge } \\
\text { rater A }\end{array}$ & $0.98 * *$ & - & - & - & - & - \\
\hline $\begin{array}{l}\text { Self-monitoring } \\
\text { rater A }\end{array}$ & - & b & - & - & - & - \\
\hline $\begin{array}{l}\text { Interpretation } \\
\text { rater A }\end{array}$ & - & - & $0.99 * *$ & - & - & - \\
\hline $\begin{array}{l}\text { Decision-making } \\
\text { rater A }\end{array}$ & - & - & - & $0.99 * *$ & - & - \\
\hline $\begin{array}{l}\text { Execution }{ }^{1} \\
\text { rater A }\end{array}$ & - & - & - & - & 1 & - \\
\hline $\begin{array}{l}\text { Negotiation and } \\
\text { use of health } \\
\text { resources } \\
\text { rater A }\end{array}$ & - & - & - & - & - & b \\
\hline
\end{tabular}

** - Correlation is significant at 0.01 ; - It cannot be calculated because at least one of the variables is constant; 1 - With deletion of item 41 (Performs the bowel irrigation technique).

Validity was first analyzed using a factor analysis to confirm the potential dimensionality of the form. Initially, we performed an exploratory factor analysis using the principal components analysis method with the eigenvalues-greater-than-one rule, without forcing the number of factors, which resulted in a six-factor structure. However, the structure resulting from the item distribution was not consistent with the theoretical construct under study. Thus, in order to maximize the item saturation, we performed another principal components analysis through Varimax rotation with Kaiser method, and then through Oblimin rotation, with the aim of forcing the grouping of items into subscales with greater theoretical consistency. However, the results were similar to those obtained in the previous analysis.

In the analysis of the convergent-discriminant validity of the item, the results were similar to the results obtained in the different attempts of factor analysis. For this reason, the convergent-discriminant validity test of the item was not included.
By studying the interdomain correlation of the form (Fortin, 2003), we intended to analyze how the construct under analysis (self-care competence) was composed of the different domains suggested in the literature. Thus, we analyzed the interdomain correlation, which showed a positive correlation, with a moderate to high and statistically significant strength of association, indicating that all domains contribute to the construct under study, despite measuring different components (Table 3).

Initially, we only found a statistically significant correlation between the Execution domain and the Self-monitoring and Negotiation and use of health resources domains, and that very few cases had been included. Thus, in an attempt to understand the underlying reasons, we analyzed the items from the Execution domain and found a very limited number of cases in which item 41 had been considered as valid. For this reason, the item was deleted, which had a significant influence in the results, as shown in Table 3 . 
Table 3

Significant correlation between the domains of the form, using Pearson's correlation test

\begin{tabular}{lccccc}
\hline & Self-monitoring & Interpretation & Decision-making & Execution ${ }^{1}$ & $\begin{array}{c}\text { Negotiation and use of } \\
\text { health resources }\end{array}$ \\
\hline Knowledge & $0.87^{* *}$ & $0.76^{* *}$ & $0.73^{* *}$ & $0.54^{* * *}$ & $0.76^{* *}$ \\
Self-monitoring & - & $0.82^{* *}$ & $0.86^{* *}$ & $0.52^{* *}$ & $0.75^{* *}$ \\
Interpretation & - & - & $0.83^{* *}$ & $0.50^{* *}$ & $0.66^{* *}$ \\
Decision-making & - & - & - & $0.58^{* *}$ & $0.70^{* *}$ \\
Execution $^{1}$ & - & - & - & - & $0.66^{* *}$ \\
\hline
\end{tabular}

** - Correlation is significant at 0.01 or less; 1 - With deletion of item 41 (Performs the bowel irrigation technique).

Therefore, given the low number of valid answers, we deleted item 41 from the analysis of correlations, which reduced the number of cases to be analyzed in the Execution domain.

To conclude the study on the metric properties of the form, we tested its clinical sensitivity (Ribeiro, 2010).

We started this process by analyzing how stoma self-care competence was influenced by the type of ostomy (temporary/permanent), without having found a statistically significant association.

We also found that patients with an informal caregiver had a lower level of self-care competence in bowel elimination ostomy in all the domains analyzed $(p<0.05)$.

To finish analyzing the sensitivity of the instrument, we associated the years of education with the self-care competence in bowel elimination ostomy. Significant differences were found in the Knowledge $(r[189]=0.20 ; p=0.005)$, Interpretation $(r[185]=0.33$; $p=0.000)$, and Decision-making $(r[168]=0.24$; $p=0.002$ ) domains, which showed a significant but weak correlation, indicating that the more years of education, the higher is the self-care competence in bowel elimination ostomy in these domains.

\section{Discussion}

The objective of this study was to assess the psychometric properties of the form Development of Self-Care Competence of the Person with a Bowel Elimination Ostomy in order to enable its use in Nursing research and clinical practice.

After the application of the form to a sample of 225 patients, we analyzed the data and tested its psychometric and clinimetric properties.

As regards its reliability, the instrument showed a good internal consistency for the total form and the corresponding domains. However, we must note that a Cronbach's alpha value of 0.95 may suggest multicollinearity, which requires further studies.

The split-half test allowed us to analyze the correlation and reliability of the instrument based on the assumption that the same individual will have a similar mean score in both halves. The results suggest a strong, significant and positive correlation between both groups. We concluded that the form is homogeneous and that, despite including different components, it assesses the same construct in a consistent manner.

As for interrater reliability, the results showed a high level of agreement. It should be noted that there is a perfect correlation in the Execution domain, possibly related to the fact that it is easier to measure given the more objective assessment of the items in this domain.

In the Knowledge, Interpretation and Decision-making domains, the values obtained were those expected since they ranged between 0.8 and 1 (Fortin, 2003), which means that the results obtained with the application of the form were not influenced by the subjectivity and characteristics of the observer.

In the Self-monitoring and Negotiation and use of health resources domains, we were not able to assess the level of interrater agreement, because at least one of the raters always reported the same value in this domain, which was then assumed as a constant variable. The same applies to the Execution domain. However, we observed that item 41 was not applicable to 25 participants and, for this reason, we deleted it. For these reasons, the results from this domain should be carefully analyzed.

For the study of validity, we based our analysis on the content validity that had been previously performed by the authors of the instrument at the time of its development. The authors used a focus group with 
experts in the area under study, who reached a group consensus.

An exploratory factor analysis through the principal components method was used to assess the construct validity. However, although a six-factor structure was obtained, these factors showed no consistency when analyzed in the light of scientific evidence and the purpose of the instrument. For this reason, we chose not to include this test.

The various interdomain correlations of the form were found to be positive and significant, ranging between 0.50 and 0.87 , which was a good indicator of their content validity and confirmed that all domains were aimed at assessing the same theoretical construct, although assessing its different components.

The Execution domain had the lowest interdomain correlation. This fact can be justified by the fact that the patent develops his/her ability to perform the procedure, but has no knowledge to sustain it. So, we found no interpretation or decision-making in stoma care.

In relation to the remaining domains, we found that the Decision-making, Execution and Knowledge domains showed a lower, although significant, correlation. This may be justified by the prevalence of unsubstantiated decision-making processes, directed only to the execution of stoma care by following and replicating a previously learned procedure.

To complete the study of the metric properties of the instrument, we analyzed its clinical sensitivity.

When analyzing the duration of the type of ostomy, Boyles (2010) argues that when the ostomy is temporary, the person does not feel the real need to totally adjust to the stoma as he/she knows that the situation is reversible.

Based on our results, we found no statistically significant association between ostomy duration (temporary/permanent) and the level of self-care competence.

When analyzing the association between the presence of a caregiver and the level of self-care competence in bowel elimination ostomy, O'Connor (2005) refers that the presence of an informal caregiver with information on stoma care is a source of safety and comfort for the ostomy patient. However, this can lead to a potential transfer of responsibilities from the ostomy patient to the informal caregiver.

In light of the above, the results obtained in this sample are consistent with the reference literature
(O'Connor, 2005) and, in fact, patients with bowel elimination ostomy who rely on an informal caregiver express a lower level of self-care competence.

Finally, as regards the variable of education, Phaneuf (2005) concludes that the level of education is one of the factors that determine the capacity to learn, whereas, in the same line, the World Health Organization reports that a low level of education negatively affects therapeutic adherence (World Health Organization, 2003).

When comparing the years of education with the level of competence, we found that in our sample, the more years of education, the greater is the level of competence of ostomy patients, namely in the Knowledge, Interpretation and Decision-making domains.

Thus, according to our results, the instrument under study meets the criteria of validity and reliability, which are necessary for it to be used in studies about the self-care competence of patients with bowel elimination ostomy, as well to monitor patients throughout the transition process.

However, some limitations of this study should be taken into account when analyzing the results of this study, using the form and planning new research. We used the nonprobability convenience sampling technique, which does not allow generalizing the results obtained to the population. Additionally, the form was only applied in the Northern region of Portugal, hence we suggest broadening the field of research.

The lack of a dedicated space to apply the instrument prevented, in some moments, the assessment of the Execution domain, which may have influenced the results obtained in this domain.

The collaboration of the nurses in data collection could also pose a risk of bias. However, measures were taken to reduce bias as much as possible through training, practical examples, a guide to form completion, and continuous monitoring. On the other hand, the presence of collaborators in the process of data collection had some positive effects, to the extent that it allowed understanding the nurses' perception of the benefits of using the instrument, as well as the difficulties experienced and possible suggestions for improvement.

Despite these limitations, the form is rigorous and has proven to be a useful tool to assess the development of stoma self-care competence, allowing to establish more personalized intervention plans. 


\section{Conclusion}

A bowel elimination ostomy is an important challenge for the health professionals, the patients and the patient's families.

Specific and systematic nursing interventions positively affect the process of stoma adjustment (Sousa, Santos, \& Graça, 2015). Therefore, the use of theoretically sound and clinically relevant instruments can help overcome the challenges resulting from this new condition, allowing nurses to guide and assess the provision of health care in a more complete, rigorous and suitable way.

The objectives set out for this study were met and we have concluded that this instrument for assessing stoma self-care competence has good psychometric and clinimetric properties, namely validity, reliability and clinical sensitivity, ensuring the veracity and plausibility of the data obtained with its application. However, the study of the instrument is in a preliminary stage and further studies are required using larger samples, as well as additional research on its clinimetric properties.

We believe that this study, besides allowing taking a further step in the knowledge about the transition experienced by ostomy patients, helps nurses to provide guidance and personalized support to patients throughout the different phases of adaptation to the new condition. Using the form will ensure the continuity of care through ongoing and rigorous monitoring, while also allowing for the record and provision of information on stoma self-care in different contexts, contributing to improve the quality of nursing care provided to the person with a bowel elimination ostomy.

\section{References}

Boyles, A. (2010). Patient outcomes and quality of life following stoma-forming surgery. Gastrointestinal Nursing, 8(8), 3035. doi: 10.12968/gasn.2010.8.8.79163

Bryman, A., \& Cramer, D. (1992). Análise de dados em ciências sociais: Introdução às técnicas utilizando o SPSS. Oeiras, Portugal: Celta Editores.

Cabral, A. (2009 Setembro). Associação Portuguesa de Ostomizados (APO). Jornal Da Secção Regional Do Centro Da Ordem Dos Enfermeiros, 20, p. 14. Retrieved from http://www.ordemenfermeiros.pt/sites/centro/informacao/ Documents/Jornal\%20da\%20SRC/jornal20.pdf
Cardoso, T. (2011). Desenvolvimento da competência de autocuidado da pessoa com ostomia de eliminação intestinal (Dissertação de mestrado). Retrieved from http:// comum.rcaap.pt/handle/123456789/9258

Fleury, M. T., \& Fleury, A. (2001). Construindo o conceito de competência. Revista de Administração Contemporânea, 5(Esp.), 183-196. doi: 10.1590/\$1415-65552001000500010

Fortin, M. F. (2003). O processo de investigação: Da concepção à realização. Loures, Portugal: Lusociência.

Gesaro, A. (2012). Self-care and patient empowerment in stoma management. Gastrointestinal Nursing, 10(2), 19-23. doi: 10.12968/gasn.2012.10.2.19

Gomes, A. M. (2012). Desenvolvimento da competência de autocuidado da pessoa com ostomia de eliminação intestinal no momento da alta do internamento (Dissertação de mestrado). Retrieved from http://comum. rcaap.pt/handle/123456789/9361

Guerreiro, M., Silva, A., Botelho, M., Leitão, O., Castro-Caldas, A., \& Garcia, C. (1994). Adaptação à população portuguesa da tradução do "Mini Mental State Examination" (MMSE). Revista Portuguesa de Neurologia, 1(9), 9-10.

O'Connor, G. (2005). Teaching stoma-management skills: The importance of self-care. British Journal of Nursing, 14(6), 320-324. doi: 10.12968/bjon.2005.14.6.17800

Phaneuf, M. (2005). Comunicação, entrevista, relação de ajuda e validação. Loures, Portugal: Lusociência.

Ribeiro, J. L. (2010). Metodologia de investigação em psicologia e saúde ( $3^{\mathrm{a}} \mathrm{ed}$.). Porto, Portugal: LegisEditora/Livpsic.

Schumacher, K., Stewart, B. J., \& Archbold, P. G., Dodd, M. J., \& Dibble, S. L. (2000). Family caregiving skill: Development of the concept. Research in Nursing \& Health, 23(3), 191-203. doi: 10.1002/1098-240X(200006)23:33.0.CO;2-B

Silva, C. R. (2012). Desenvolvimento da competência de autocuidado da pessoa que vai ser submetida a ostomia de eliminação intestinal (Dissertação de mestrado). Retrieved from http://comum.rcaap.pt/handle/123456789/9291

Simmons, K. L., Smith, J. A., Bobb, K. A., \& Liles, L. L. (2007). Adjustment to colostomy: Stoma acceptance, stoma care self-efficacy and interpersonal relationships. Journal of Advanced Nursing, 60(6), 627-635. doi: 10.1111/j.13652648.2007.04446.x

Sousa, C. F., Santos, C., \& Graça, L. C. (2015). Construção e validação de uma escala de adaptação a ostomia de eliminação. Revista de Enfermagem Referência, 4(4), 21-30. doi: 10.12707/RIV14021

World Health Organization. (2003). Adherence to long-term therapies: Evidence for action. Retrieved from http://apps. who.int/iris/bitstream/10665/42682/1/9241545992.pdf" 
